\title{
Speech Act of Complaints From Online Hotel Review
}

\author{
Faisal Fahdian Puksi \\ Sekolah Tinggi Pariwisata Bandung \\ Bandung, Indonesia \\ faisalpuksi@gmail.com
}

\begin{abstract}
The aim of this research is to identify speech act of complaint in online hotel review. It can be used to explain the complaints intention from guest to hotel. Hoteliers can also provide better services if they know what to do in dealing with negative guest comments. This research employed descriptive approach by collecting data from websites that provide online hotel review platforms. Previous guest's complaints, is observed and cited to get written hotel guest complaints data. Classification that were used to determine speech act of complaint are from Murphy and Neu (1996), Tabatabaei (2015), and Olshtain and Weinbach (1987). There are several findings that can be taken from this research. The results showed. Complaint strategy as a part of speech act of complaint has the highest percentage for appearance frequency in online hotel review. Threat strategy also becomes alternative strategy for speech act of complaint from hotel guest in online hotel review. There is no apology strategy for speech act of complaint in online hotel review. There is no attempt to save face of face-threatening act from speaker (hotel guest/ reviewer) to hearer (hotel management) in online hotel review.
\end{abstract} review.

Keywords - speech act; complaints, hotel guest review, online

\section{INTRODUCTION}

The complex nature of services always becomes the main issue in hotels' service businesses. Assessment and understanding of guests' standards are very important to identify quality services as well as guests' satisfaction [1]. Hotel guests' satisfaction play a very important role in the hotel business success. Satisfied and pleased hotel guest tend to remain loyal, repeat their visit, spread positive word of mouth.

The development of internet which is increasingly accessible anytime and anywhere makes things very easy to find any information. One of the most frequently searched on the internet is online hotel booking services including hotel review. Hotel reservations are now widely changed, from traditional telephone booking system into an online booking system that leveraged by internet technology. Additionally, the service provider of online hotel review becomes a base for customers in choosing the hotel. Two-way communication between the customer and the hotel has becoming rare occasion, multi directional communication on the internet has become a very important system in the development of the hotel business.
Online hotel review can be place for hotels to promote its products. On the other hand, customer can provide positive and negative reviews. Customers can express a favorable impression when using the services of the hotel to be read by everyone. However, usually when prospective hotel guests read reviews that are positive, they may find that the review does not correspond to the actual situation. Prospective hotel guests are usually more easily influenced by negative reviews. Negative review can determine over prospective hotel guests' decision making process in selecting a hotel. Most of negative reviews that appear in online hotel review provider are complaint [9], [13].

In daily life, people often feel annoyed, discontented, or not happy with circumstances or the attitudes of others. This uncomfortable situation often leads people to express their feeling by complaining. In complaining, they expressed feelings of dissatisfaction with other people or circumstances by choosing certain words that depend on some factors such as social status, gender, relationship between interlocutors, and the complexity of the situation [4]. Speech acts of complaint can be face-threatening act when the speaker violated sociocultural rules. This can lead to disruptions in communication and potentially damage the speaker's relationship with the hearer. According to [6] speech act depends on the situation with the speakers must know how to perform speech acts by considering some aspects, such as the hearer, the relationship with the hearer, the topic, the purpose of conversation, and the suitability of the linguistic form. Thus, the speakers are expected to have a socio-cultural competence in language and linguistic in order to perform speech acts accordingly.

Research on speech acts may provide new insights in the understanding and the correlation between the form of linguistic and socio-cultural context [6]. Previous research on speech acts of complaint focuses on cross-cultural and native speakers [6], [10], the comparison of rejections and complaints [11], the use of methods of DCT in getting data [6], [10], [11]. From previous studies, very few studies evaluated the speech acts of complaint from hotel guests on the online hotel review providers. Study from [1] give enough idea about the response of hotel in communicating with hotel guests through Tripadvisor. However, speech act of complaint did not highlighted on previous study. This study focuses on 
identifying forms of speech acts of complaint that appears in online hotel review.

\section{LITERATURE REVIEW}

\section{A. Speech Act}

The concept of speech act was first introduced by J.L. Austin in 1962 to show that the speaker does not only produce utterances to convey information, speaker also produces utterances to do something or make others do something [10]. Speech that is used to realize an apology, promise, request, refuse, complaint, and so on then called 'speech acts'. As a linguistic competence, speech acts in other words means that says something meaningful to do an action.

According to [10], there is debate about the universality of speech acts. Some researchers such as Austin, Searle, and Leech claimed that the speech act have function through the principle of universal pragmatics. On the other side, researchers such as Wierzbicka, Einstein and Bodman stated that aspects of speech acts are not universal and vary between languages with one another.

Searle (1979) in [10] classify speech acts into five basic categories, Representative speech acts, Directive speech acts, Commissive speech acts, Declarative speech acts, Expressive speech acts.

\section{B. Speech Act of Complaint}

Complaint is the expression of a psychological state that not satisfied or unhappy about something [10]. According to [6], [10], [11], in speech act of complaint, the speaker reacts with unhappy or irritated actions that in a way that is not desirable. Speech act of complaint have face-threatening act consequences, so speech act of complaint must be done with cautious by the speakers as not to offend the hearer's face or feeling and good relations between speaker and hearer can be maintained [6].

Searle (1976) in [10] incorporate complaint as part of expressive speech acts relating to the psychological state annoyed expression. Speech act of complaint is different with critics. Compared to the complaint, the choices of language in critics are more robust, rude, condescending, and direct [6]. Olshtain \& Weinbach (1987) in [6] identified the conditions that must exist in speech act of complaint. These conditions indicate what makes the speaker and hearer speaks, what was said, and what the purpose of complaining. The terms of the emergence of speech act of complaint are:

1. Speaker expects the expected events (appointments, return of debts, the fulfillment of a promise, and others) or prevents the occurrence of unexpected events (cancellation, destruction, humiliation, and others). The results of this aspect are the speakers' expectations do not match or fails to prevent an embarrassing incident.

2. Speaker looked at previous action have unintended consequences for offending speakers.
3. The speaker considers that the hearer is responsible for the previous actions.

4. The speaker chooses to express a sense of disappointment and frustration.

Negative face-threatening speech act of complaint for hearer is free from a burden that often arise when complaint accompany by a request for compensation. Positive face is for hearer who feels like to be appreciated and valued can also be threatened when the speaker did speech act of complaint.

Reference [10] describes the complaint as illocutionary acts with speakers denounce or other negative feelings in a particular issue with the speakers felt hearer as a responsible party in the matter, either directly or indirectly. In performing speech act of complaint, the speaker can use a combination of several strategies to complain [8], [11], [10].

Taxonomy speech act of complaint by [8] is divided into five parts, namely:

\section{Complaint}

a. The use of the pronoun "we" in two different ways: 1) to indicate that both sides share the blame. 2) as a way of negotiating the problem.

b. Use these questions to ask advice, permission to explain the circumstances, or to invite the hearer to discuss problems.

c. Depersonalization problem, replace the blame of the hearer to the problem.

d. The use of mitigation (such as, perhaps, possibly, a little bit, somehow, I thought, I'm afraid, I mean, do you think) is to soften the complaint.

\section{Justification}

Speaker use justification by giving reason for an action that causes the hearer in a positive position.

\section{Criticism}

a. The use of the second person + preposition 'must' which indicates that the speaker is in a position to dictate the behavior of hearer.

b. Personalization problem put the blame on the hearer.

c. Refusal to accept the responsibility of the problem.

When using the strategy of criticism, the speaker tried to directly notify hearer for errors and may prolong the problem or give a reason. This strategy usually involves accused words (you should ... you never ...) and scorn and direct words that might attack personal character of the hearer.

\section{Explanation of purpose}

Speakers explained the purpose in starting a conversation.

\section{Candidates' solution}

Speakers offer solutions to resolve the issue. Therefore, it is usually divided into two types, which have the authority 
usually demands (demand) and the lack of authority usually ask (request).

a. demand

i. The first person singular + 'want', 'demanding', 'urgent'.

ii. Second-person pronoun + 'shall', 'should'.

b. request

The use of words 'can' and 'will' which shows decency.

Reference [10] adds three more types into taxonomies of speech act of complaint.

\section{Sarcasm}

Bite comments, false humor, or exaggerated statements designed to hurt and insinuated hearer into positive action. Sarcasm is the lowest form of humor.

\section{Threat}

This strategy is used to express the negative consequences for behavior that is not beneficial for hearer. This can cause the hearer to feel offended because the speaker threatens the hearer.

\section{Apology}

Speaker use apology strategies to reduce the negative effects of a complaint to the hearer. It is usually used when complaining to someone of higher social status and is considered as a marker of politeness.

Reference [11] use five categories speech act of complaint from Olshtain and Weinbach (1987):

1. Below the level of reproach.

2. Disagreement.

3. Complaints.

4. Charges and warnings.

5. Threat.

\section{Online Hotel Review}

Online hotel review providers have a major role in the development of the hospitality industry [12]. Unfortunately, not all understand the implications that may arise from the development of online hotel guest review [13]. Most popular online hotel review websites in Indonesia usually also have reservation services, such as Agoda.com, Traveloka.com, Booking.com, and others. Tripadvisor.com previously only provides hotel review without reservation services. However, Tripadvisor.com started in 2015 has started providing online hotel booking services.

Agoda Company Pte Ltd is an Online Travel Agency based in Singapore offering accommodation booking services through websites and mobile phone applications. Agoda.com offers service with 38 different languages, with different types of accommodation, from hotels, B \& Bs, beach resorts, up to the homestay. Traveloka is a company that provides services and hotel booking air tickets online with a focus on domestic travel in Indonesia. Traveloka have operational base in Jakarta. Booking.com is the online accommodation booking online began in 1996, based in Amsterdam, the Netherlands, and since 2005 and base of operations is located in Bellevue, WA, USA. Booking.com claims to have over 700,000 global hotel partners. TripAdvisor, Inc. is an American company of travel sites that provide reviews on travel-related content, including hotels and restaurants. TripAdvisor is the first user of user-generated content that provides services free of charge to the user online, most of the content developed by users, and is supported by advertising business model.

Review of hotel guests online has become an important aspect for prospective guests' consideration in determining hotel selection. There is a correlation between the levels of satisfaction of hotel guests with the hotel's response to the complaint on the page hotel review providers [1]. Prospective guests will find out how the hotel responds to every complaint before deciding to stay at the hotel.

When seeing the reviews from previous hotel guests, prospective guests consider the hotel reviews based on positive reviews, negative reviews, and the depth of commentary [7]. However, when a prospective hotel guests read reviews that are positive, they felt that the review was dishonest or hiding something. Prospective hotel guests are usually more easily influenced by negative reviews. Negative reviews determine prospective guest decision making process in selecting a hotel. The negative reviews that appear in online hotel review provider is usually a complaint [13], [9]. According [1] complaints submitted online can be divided into two, namely the core systems business and customer service. Issues in the hotel business core system related with problem from hotel products, such as the shabby decor, the bed was dirty, the rooms are full. Issues in customer service at the hotel are concerned with how the hotel guests were treated by the hotel staff.

\section{METHODOLOGY}

This descriptive study aims to understand the social phenomenon that included linguistic phenomenon which analyze the data with all the characteristics, nature and character that will produce findings [5].

This research applies content analysis method, by performing linguistic analysis on the speech act of complaint from hotel guests on the online hotel review. The analysis is done by identifying the speech acts complaint that appears on the online hotel review, both in Indonesian and English.

Data in this study are secondary data sources, which is hotel guest reviews on the four online hotel reviewers, namely Agoda.com, Traveloka.com, Booking.com, and Tripadvisor.com. The four online hotel review providers are selected because of the popularity of the websites among hotel guests. Researchers in this study only restrict to only take 200 
hotel guests' speech act of complaint from 2015-2016 in order to represent the entire data.

\section{FINDINGS AND DISCUSSION}

This study is focusing its research only to identify speech act of complaint from online hotel review. In the process of identifying speech act of complaint, three taxonomy of Speech Act of Complaint from [8], [10], and Olshtain and Weinbach (1987) in [11].

Reference [8] divide taxonomy of speech act of complaint into five components: complaint, justification, criticism, explanation of purpose, and candidate's solution.

Table 1 Result Online Hotel Review based on Murphy and Neu (1996) Speech Act of Complaint Taxonomy

\begin{tabular}{|c|l|c|c|}
\hline No. & Types of Complaint & $\begin{array}{c}\text { Total } \\
(\mathbf{N = 2 0 0 )}\end{array}$ & $\begin{array}{c}\text { Frequency } \\
\text { (\%) }\end{array}$ \\
\hline 1 & Complaint & 135 & 67.5 \\
\hline 2 & Justification & 92 & 46 \\
\hline 3 & Criticism & 94 & 47 \\
\hline 4 & Explanation of Purpose & 7 & 3.5 \\
\hline 5 & Candidate's Solution & 24 & 12 \\
\hline
\end{tabular}

As can be seen in table 1, 67.5\% hotel guests produced complaint speech act to express their feeling about hotel where they stayed. The topic of their complaints generally concerned about facilities and services.

(a) "We did request to change room but no feedback at all."

(b) "The hotel was too noisy if there is an event going on. Can hotel set up decoration to prevent to hear the noisy from inside the room?"

$47 \%$ of hotel guest write Criticism speech act in online hotel review. Same as Complaints speech act, Criticism speech act also focusing complaints to facilities and services.

(c) "Overall was alright, only the room is old and the hotel should put more attention for the cleanliness of the hotel, breakfast was so so, you could do better for 4 star hotel, but location and price is quite cheap for the high season rate."

(d) "...room water heater is not working well. My 19 months toddler have to shower in cool water. let's hope he is okay."

Different from Complaint and Criticism speech act, Justification speech act with $46 \%$ speech act of complaint utterances from hotel guest mention the amount of money they have spent to stay in the hotel.

(e) "Since I just need hotel for sleep, I think this hotel is representative. But don't expect more, the pool was very dark at night, and very confusing between building 1 and 2. For 3 star hotel, I think quite worth but I don't agree if this hotel classify as 4 star hotel."
Some speech act of complaint can be classified as Candidate's Solution with 12\%, for example:

(f) "The towel, the room interior and carpet is not clean enough. There was a problem with air con. I think the maintenance has to be improved."

Explanation of purpose strategy from speech act of complaint has the lowest percentage in online hotel review with $3.5 \%$. The sample of utterance for explanation of purpose strategy is:

(g) "Since I just need hotel for sleep, I think this hotel is representative. But don't expect more, the pool was very dark at night, and very confusing between building 1 and 2. For 3 star hotel, I think quite worth but I don't agree if this hotel classify as 4 star hotel."

Classification for speech act of complaint also has been made based on [10] Speech Act of Complaint. [10] research added three more components to previous research by [8]. Reference [10] added Sarcasm, Threat, and Apology.

Table 2 Result Online Hotel Review based on Tabatabaei (2015) Speech Act of Complaint Taxonomy

\begin{tabular}{|c|l|c|c|}
\hline No. & Types of Complaint & $\begin{array}{c}\text { Total } \\
(\mathbf{N = 2 0 0 )}\end{array}$ & $\begin{array}{c}\text { Frequency } \\
\text { (\%) }\end{array}$ \\
\hline 1 & Sarcasm & 14 & 7 \\
\hline 2 & Threat & 102 & 51 \\
\hline 3 & Apology & 0 & 0 \\
\hline
\end{tabular}

Threat, which occurred $51 \%$ in online hotel review was more used more frequently through hotel guest complaints. Speaker tends to give bad recommendation to other prospective hotel guest about staying in same hotel. Sample of utterance is:

(h) "I stayed in the superior room with breakfast. The room is really bad since it's really small. I expected more considering it's a five star hotel. The only good thing about this hotel is the view and it's ok breakfast. Won't come back here again."

Regarding Sarcasm, 7\% parts from speech act of complaint use sarcastic strategy.

(i) "Take Iday for the staff to open the connecting door. Towel is not so clean. Let's call it cockroach hotel. I think I stay in a cockroach nest."

Interestingly, data also shows that no person write complaint in online hotel review with apology strategy. This shows that speaker did not afraid with negative effect of the complaint on the hearer. Because of the communication system, speaker (hotel guest) cannot see hearer (hotel).

As can be seen in table 3, Olshtain and Weinbach (1987) in [11] made classification for speech act of complaint into 5 components, including below the level of reproach, disagreement, complaints, charges and warnings, and threat. 
Table 3 Result Online Hotel Review based on Olshtain and Weinbach (1987) Speech Act of Complaint Taxonomy

\begin{tabular}{|c|l|c|c|}
\hline No. & \multicolumn{1}{|c|}{ Types of Complaint } & $\begin{array}{c}\text { Total } \\
(\mathbf{N = 2 0 0 )}\end{array}$ & $\begin{array}{c}\text { Frequency } \\
(\mathbf{\%})\end{array}$ \\
\hline 1 & Below the level of reproach & 12 & 6 \\
\hline 2 & Disagreement & 58 & 29 \\
\hline 3 & Complaints & 135 & 67.5 \\
\hline 4 & Charges and Warnings & 31 & 15.5 \\
\hline 5 & Threat & 102 & 51 \\
\hline
\end{tabular}

Result from table 3 show that complaints strategy of speech act of complaint still has the most utterances with $67 \%$ compared with other components.

(j) "The room and its facility are far from my expectation as 4 stars hotel. The bed are not good and comfort enough. The room wasn't cleaned by the hotel until we asked it."

Threat has a significant percentage with more than half (51\%) utterances employ this strategy to complain.

(k) "This visit was my return. I little bit disappointed with the room condition. The food also not so excited anymore. I will think twice to choose this hotel."

\section{CONCLUSION AND RECOMMENDATION}

This research had identified speech acts of complaint from online hotel review. Through the process of identifying speech act of complaints in online hotel review, it can be found several findings.

Complaint strategy as a part of speech act of complaint has the highest percentage for appearance frequency in online hotel review. Complaint as strategy usually employ words 'we' to share the blame and negotiating problem, use questions to ask for advice and explanation, replace the blame of the hearer to the problem, and use mitigation to soften the complaint.

Threat strategy also becomes alternative strategy for speech act of complaint from hotel guest in online hotel review. This strategy is used to express the negative consequences for behavior that is not beneficial for hearer. This can cause the hearer to feel offended because the speaker threatens the hearer.

There is no apology strategy for speech act of complaint in online hotel review. This shows that internet (online review) has the effect of how people complain. There is no attempt to save face from speaker (hotel guest/ reviewer) to hearer (hotel management).
This research has some limitation when it comes to sample size for speech act of complaint from online hotel review. 200 samples for this kind of study was extremely small compared to the size of complaint utterances in online hotel review data.

There are several suggestion for further research related with speech act of complaint in online hotel review. With larger sample, this research can be developed by employing hotel response to guest complaint in online hotel review. This research can also be developed with complaint correlation with intent of stay from prospective guest. Across-cultural linguistic can be also employed for further research to gain perspective from different language based on nativity.

\section{REFERENCES}

[1] Avant, T. L., "Responding to tripadvisor: How hotel responses to negative online reviews effect guest perception of image, guest intent to stay, and guest intent to return", Doctoral dissertation, University of South Carolina, 2013.

[2] Berry, L.L. and Parasuraman, A. Marketing services: Competing through quality. The Free Press: NY. 1991

[3] Creswell, John W., "Research Design: Pendekatan Kualitatif, Kuantitatif dan Mixed”. Yogyakarta: Pustaka Pelajar, 2010.

[4] Sukyadi, D and Dyah Ayu, Complaining in EFL Learners: Differences of Realizations between Men and Women (A case study of Indonesian EFL learners at the English Department of the Indonesian University of Education). "PAROLE-Journal of Linguistics and Education", 2(1 April), 1-25, 2012.

[5] Fraenkel, Jack. R dan Norman E. Wallen, "How To Design and Evaluate Research In Education", New York: McGraw-Hill International Edition, 2008.

[6] Moon, K., "Speech act study: Differences between native and nonnative speaker complaint strategies". The American University, 2001.

[7] Mudambi, S. M., \& Schuff, D., What makes a helpful online review? A study of customer reviews on amazon.com. "MIS Quarterly, 34(1)", 185-200, 2010.

[8] Murphy, B., dan Neu, J., My grade's too low: The speech act set of complaining. "Speech acts across cultures: Challenges to communication in a second language", 191-216, 1996.

[9] Papathanassis, A., \& Knolle, F., Exploring the adoption and processing of online holiday reviews: A grounded theory approach. "Tourism Management, 32(2)", 215-224, 2011.

[10] Tabatabaei, S., Realization of Complaint Strategies by English and Persian Native Speakers. "MJAL, 7(1)", 123-145, 2015.

[11] Tanck, S., Speech act sets of refusal and complaint: A comparison of native and non-native English speakers' production. "Studies in Second Language Acquisition". American University, Washington, DC, 2002.

[12] Tantawy, A., \& Losekoot, E., An assessment of key hotel guest contact personnel in handling guest complaints. "Journal Of Quality Assurance In Hospitality \& Tourism, 1(4)", 21, 2001.

[13] Xie, H. J., Miao, L., Kuo, P. J., \& Lee, B. Y., Consumers' responses to ambivalent online hotel reviews: The role of perceived source credibility and pre-decisional disposition. "International Journal of Hospitality Management, 30(1)", 178-183, 2011. 